\title{
Особенности свойств редкоземельных полупроводников
}

\author{
(C) В.В. Каминский, Н.В. Шаренкова \\ Физико-технический институт им. А.Ф. Иофрфе Российской академии наук, \\ 194021 Санкт-Петербург, Россия \\ E-mail: Vladimir.kaminski@mail.ioffe.ru
}

(Получена 17 апреля 2018 г. Принята к печати 21 августа 2018 г.)

Показано, что уникальные особенности физических свойств редкоземельных полупроводниковых соединений имеют в своей основе малые величины ионизационных потенциалов редкоземельных элементов в них. Причиной этого является наличие $4 f$-оболочек в электронной структуре элементов.

DOI: $10.21883 /$ FTP.2019.02.47091.8893

Полупроводниковыми свойствами обладают следующие группы редкоземельных соединений: монохалькогениды редкоземельных элементов (Р3Э/REE), имеющие устойчивое двухвалентное состояние; твердые растворы монохалькогенидов двух- и трехвалентных РЗЭ; соединения состава $\mathrm{Ln}_{2} \mathrm{X}_{3}$ и $\mathrm{Ln}_{3} \mathrm{X}_{4}$, промежуточные составы $\mathrm{Ln}_{2} \mathrm{X}_{3}-\mathrm{Ln}_{3} \mathrm{X}_{4}$ ( $\mathrm{Ln}$ - лантаноид, $\mathrm{X}$ - халькоген). Редкоземельные полупроводниковые материалы (РЗП) выделяются среди других групп полупроводников наличием некоторых ярко выраженных эффектов и рекордных электрических параметров. Сюда можно отнести минимальное давление всестороннего сжатия для возникновения фазового перехода полупроводник-металл [1], наличие фазового перехода полупроводник-металл при одноосном сжатии образца [2] и при полировке его поверхности [3], максимальную величину тензорезистивного эффекта [4], максимальную величину термовольтаического эффекта [5], наибольшую чувствительность электросопротивления тонких пленок к молекулам осажденного на их поверхности газа [6]. Некоторые из этих свойств находят практическое применение при создании первичных полупроводниковых преобразователей с рекордными эксплуатационными параметрами, поэтому объяснение природы особенностей свойств РЗП является актуальной задачей.

При анализе механизмов всех перечисленных эффектов обращает на себя внимание тот факт, что все они связаны с переходами электронов из различных локализованных энергетических состояний в зону проводимости. Целью настоящей статьи является попытка объяснения уникальности свойств РЗП и в какой-то мере редкоземельных соединений (РЗС) вообе исходя из самых общих представлений о строении атомов.

Постараемся объяснить на качественном уровне основные особенности РЗС и РЗП, не вдаваясь в подробности и не заостряя внимания на некоторых деталях и исключениях из основной тенденции, которые встречаются на пути такого изложения проблемы и которые имеются и в самой Периодической системе Д.И. Менделеева в ее элементарном изложении.

В полупроводниках для перехода электрона в свободное состояние (зону проводимости) наиболее важным параметром следует считать величину ионизационного потенциала $(I)$ элемента. Это следует из того, что при грубой оценке глубина залегания примесного донорного уровня в полупроводниковом материале $E_{i}=I / \varepsilon_{2}$, где $\varepsilon$ - диэлектрическая проницаемость [7]. Рассмотрим ионизационные потенциалы элементов Периодической системы. Поскольку мы анализируем не элементы, а соединения элементов, которые состоят из их ионов, нас будут интересовать только величины второго $\left(I_{2}\right)$ и третьего $\left(I_{3}\right)$ ионизационных потенциалов (первый относится к атомам). Кроме того, мы не будем рассматривать элементы, не представляющие интереса для изготовления практически применимых материалов. Это прежде всего радиоактивные элементы, которые имеют порядковый номер $Z>83$, и инертные газы. На рис. 1 представлены второй и третий ионизационные потенциалы. Как видим, редкоземельные элементы имеют наименьшие значения ионизационных потенциалов. Можно сделать вывод, что РЗЭ, введенный в матрицу из какого-либо соединения (не обязательно полупроводникового), будет наиболее легко отдавать свой электрон по сравнению со всеми другими элементами. В полупроводниках электрон будет попадать в зону проводимости и приводить к возникновению связанных с таким переходом эффектов.

Причина малости ионизационных потенциалов по сравнению с другими элементами может быть связана с тем, что ионы РЗЭ имеют наибольшие размеры ионных радиусов (см., например, для трехвалентных ионов рис. 2). Это соответствует общей тенденции уменьшения ионизационных потенциалов с увеличением радиуса атомов $\left(r_{0}\right)$ и ионов $\left(r^{3+}\right)$ (рис.3). Большие радиусы атомов и ионов РЗЭ $\left(R_{4 f}\right)$ связаны с наличием у них электронов, локализованных на $4 f$-оболочках. Эти оболочки находятся наиболее близко к ядру элемента, и их электроны в существенной степени экранируют кулоновский потенциал ядра, что приводит к увеличению ионного радиуса. На рис. 4 в качестве примера приведено радиальное распределение плотности заряда для $4 f-, 5 s-, 5 p-$ и $6 s$-электронов иона $\mathrm{Gd}^{3+}[8]$. Как видим, максимальную плотность электронов имеют $4 f$-оболочки, и расположены они наиболее близко к ядру (расстояние $r=0.3 \AA$ ). Наличие $4 f$-оболочек и определяет уникальность свойств РЗП. Появление аналогичных свойств можно ожидать только в актиноидах с 

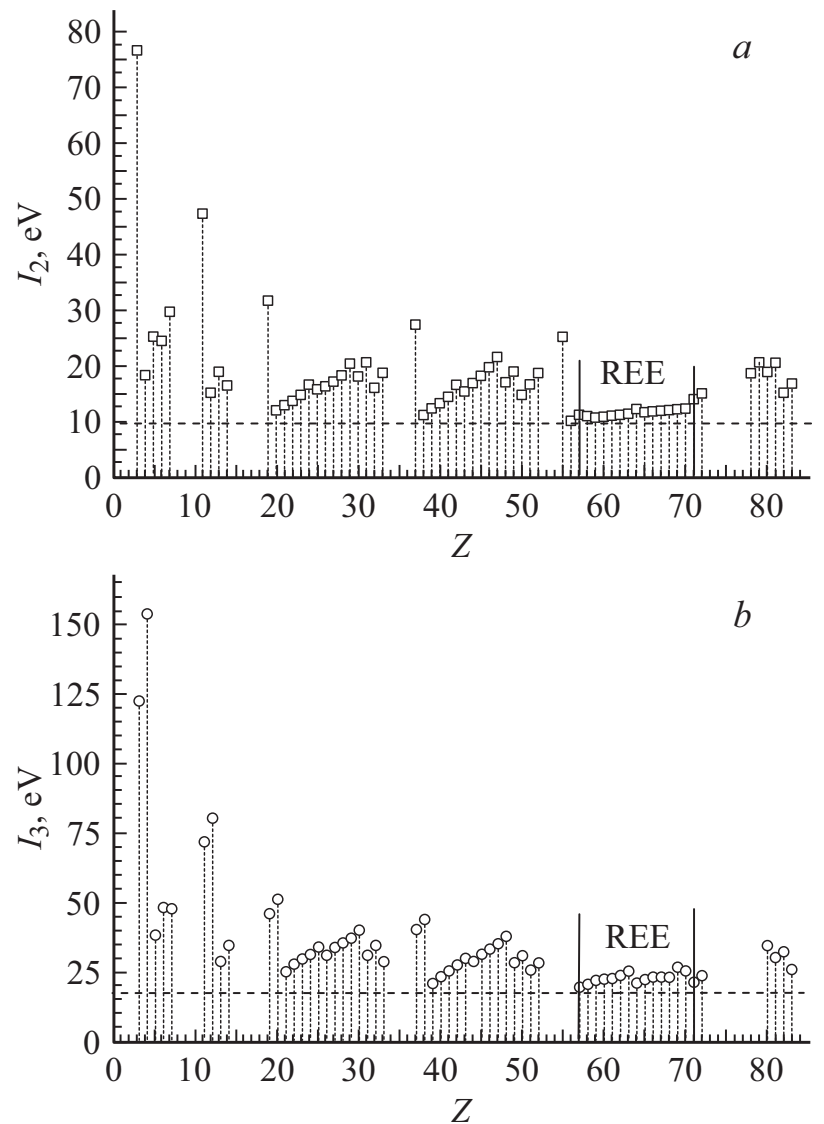

Pис. 1. Зависимости второго ионизационного потенциала (a) и третьего ионизационного потенциала $(b)$ от порядкового номера элемента.

большими атомными номерами, в которых $5 f$-оболочки также локализованы [9]. Однако практическое применение этих свойств невозможно из-за высокой радиоактивности актиноидов.

Описанная особенность свойств редкоземельных соединений позволяет определить круг наиболее целесообразных практических применений РЗП. Поскольку редкоземельный ион в этих соединениях наиболее легко отдает свой электрон при различных внешних воздействиях, эти материалы могут применяться в качестве чувствительных элементов при изготовлении датчиков различных физических величин резистивного типа (механических, тепловых и газовых сенсоров), а также в преобразователях различных видов энергии в электрическую. Наибольший интерес в этом смысле представляет сульфид самария ( $\mathrm{SmS})$, поскольку в этом полупроводнике $4 f$-уровни иона самария локализованы в запрещенной зоне наиболее близко к дну зоны проводимости $(\sim 0.2$ эВ) среди других РЗП. Следует отметить, что РЗП плохо подходят для изготовления элементной базы классической электроники, поскольку их электрические параметры чувствительны к внешним воздействиям. Малые величины ионизационных потенциалов РЗЭ определяют также эффективность применения РЗС в

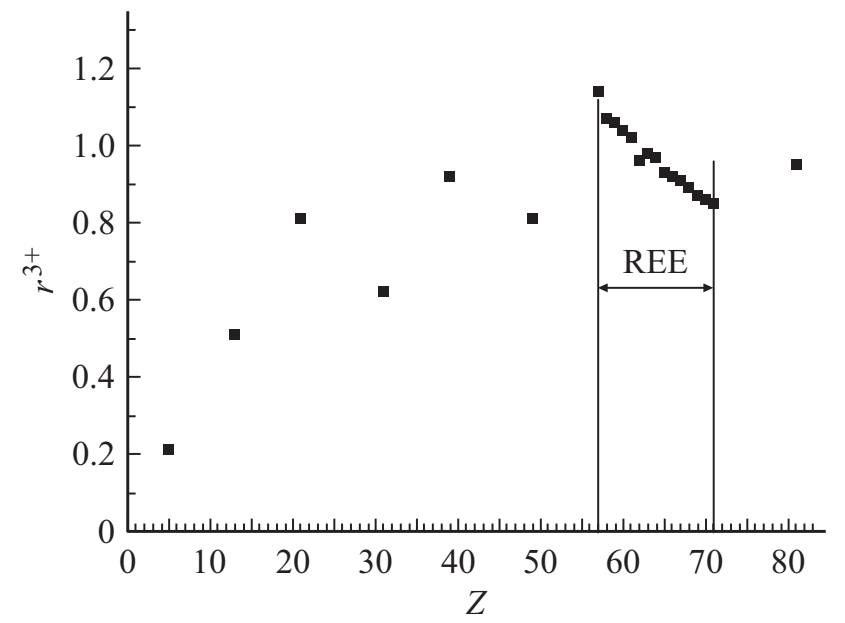

Рис. 2. Зависимость радиусов трехвалентных ионов элементов Периодической системы от их порядкового номера.

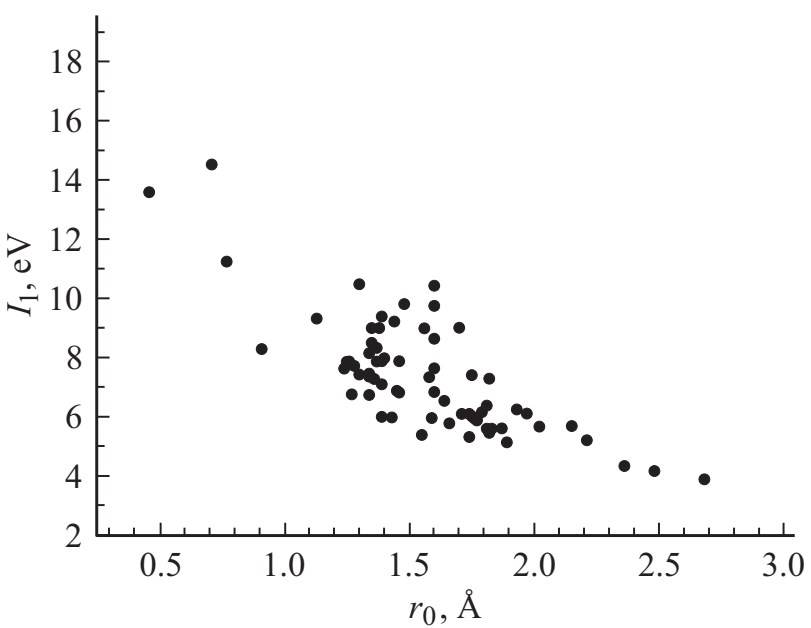

Рис. 3. Зависимость первого ионизационного потенциала от атомного радиуса всех элементов, за исключением радиоактивных и инертных газов.

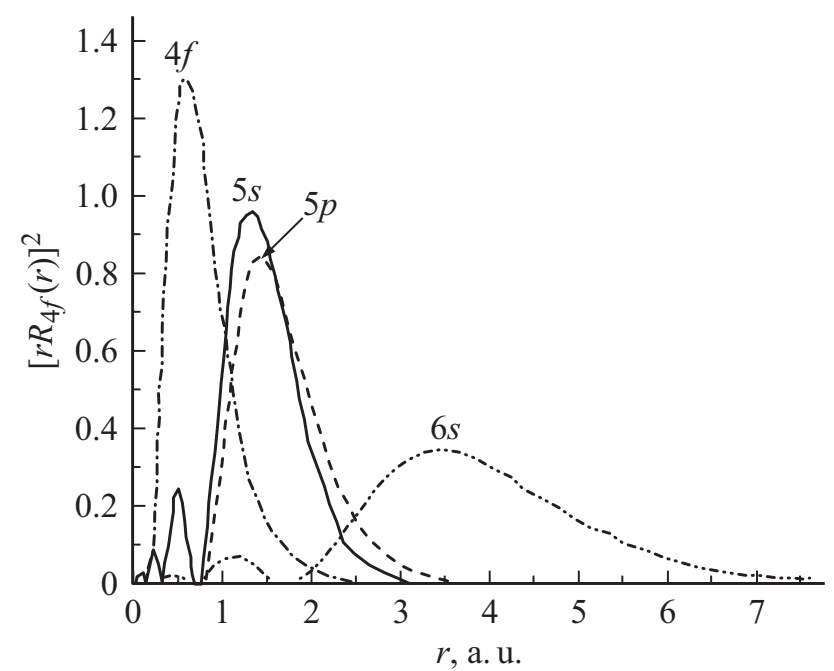

Рис. 4. Радиальное распределение плотности заряда для $4 f$-, $5 s-, 5 p$ - и $6 s$-электронов иона $\mathrm{Gd}^{3+}$. 
качестве катодов, люминофоров, лазерных материалов, неорганических пигментов и др.

Однако при развитии технологий изготовления различных чувствительных структур датчиков и преобразователей на основе РЗП встречаются трудности, выражающиеся в сложности воспроизводимости результатов технологических процессов и большом разбросе параметров готовых изделий по сравнению с таковым при изготовлении структур на основе других полупроводниковых материалов. Эти сложности являются обратной стороной достоинств РЗП. Они связаны с тем, что ионы РЗЭ легко изменяют свою валентность при внешних воздействиях. Это приводит к необходимости чрезвычайно точного соблюдения всех параметров технологических процессов. По мере развития технологии эти трудности будут преодолеваться, и структуры на основе РЗП будут находить все большее практическое применение.

\section{Список литературы}

[1] A. Jayaraman, V. Narayanamurti, E. Bucher, R.G. Maines. Phys. Rev. Lett., 25 (20), 1430 (1970).

[2] В.В. Каминский, А.А. Виноградов, Н.Н. Степанов, И.А. Смирнов. Письма ЖТФ, 9 (10), 624 (1983).

[3] В.П. Жузе, А.В. Голубков, Е.В. Гончарова, Т.И. Комарова, В.М. Сергеева. ФТТ, 6 (1), 268 (1964).

[4] В.В. Каминский, А.В. Голубков. ФТТ, 21 (9), 2805 (1979).

[5] М.М. Казанин, В.В. Каминский, С.М. Соловьев. ЖТФ, $70(5), 136$ (2000).

[6] С.А. Казаков, В.В. Каминский, С.М. Соловьев, Н.В. Шаренкова. Научное приборостроение, 25 (3), 116 (2015).

[7] А.Ф. Иоффе. Физика полупроводников (М.-Л., АН СССР, 1957).

[8] К. Тейлор, М. Дарби. Физика редкоземельных соединений (М., Мир, 1974) с. 20. [Пер. с англ.: K.N.R. Taylor, M.I. Darby. Physics of Rare Earth Solids (Chapman and Hall LTD, London, 1972)].

[9] В.Ю. Ирхин, Ю.П. Ирхин. Электронная структура, физические свойства и корреляционные эффекты в $d$ - и $f$-металлах и их соединениях (Екатеринбург, УрО РАН, 2004).

Редактор Л.В. Шаронова

\section{Features of rare-earth semiconductors properties}

V.V. Kaminski, N.V. Sharenkova

loffe institute, 194021 St. Petersburg, Russia

Abstract In the paper it is shown that the unique features of the physical properties of rare-earth semiconductor compounds are based on small values of the ionization potentials of rare-earth elements. The reason is the presence of $4 f$-shells in the electron structure of the elements. 